\title{
The Initiation of Phasic and Tonic Contraction by Potassium and the Effect of Calcium, Multivalent Cations and Ca-antagonist on Potassium Contracture in Guinea-pig Vas Deferens
}

\author{
Mitsuhiro SHImodan and Satoru SunANo \\ Department of Physiology, Sapporo Medical College, \\ S. 1, W. 17, Sapporo, 060 Japan
}

\begin{abstract}
The role of $\mathrm{Ca}$ in phasic and tonic contractions of high-Kinduced contractures of guinea-pig vas deferens was studied. It was shown that phasic contraction was initiated by a burst of action potentials, and tonic contraction by sustained depolarization. Phasic contraction seemed to be related to the rate and degree of depolarization, whereas tonic contraction seemed to be related only to the degree of depolarization.

Tonic contraction was more sensitive to a reduction of extracellular $\mathrm{Ca}$, though both types of contraction were abolished by $\mathrm{Ca}$ removal. The tonic contraction observed with isotonic recording was more sensitive to extracellular $\mathrm{Ca}$ than that observed with isometric recording. Maximum contractions were achieved with lower $\mathrm{Ca}$ than that in isometric measurement. Verapamil blocked tonic contraction at a low concentration, and both contractions at a high concentration. $\mathrm{Mn}$ or $\mathrm{La}$ blocked the phasic and tonic contractions first. After prolonged exposure to either ion, however, tonic contraction could be induced. The results suggest that both phasic and tonic contractions were induced by Ca-influx through the cell membrane, and that tonic contraction was maintained by a constantly elevated intracellular $\mathrm{Ca}$ concentration which is the consequence of an altered equilibration of $\mathrm{Ca}$ influx and $\mathrm{Ca}$ extrusion through the cell membrane.
\end{abstract}

The contractile responses of smooth muscles to a high concentration of potassium (high-K) have been shown to be composed of two or more components of contraction (URAKawa and Holland, 1964; Chapman and Holman, 1968; SunANo and MryazaKi, 1975; Swamy et al., 1976). Although the importance of $\mathrm{Ca}$ in high-K-induced contractures has been emphasized, there still remains the uncertainty of its role with respect to each component, various assumptions having been made (URAKAWA and Holland, 1964; IMAI and TAKeDA, 1967;

Received for publication June 23, 1980

下段光裕, 砂野 哲 
SunANo and MiYazaki, 1968). Most of the recent work on high-K-induced contractures in various types of smooth muscle are in agreement that the contractures are highly dependent on extracellular Ca (KURIYAMA et al., 1976; JoHNISHI and SUNANO, 1978; ROSENBERGER et al., 1979).

The high-K-induced contracture of guinea-pig vas deferens is composed of a phasic component and a tonic component, which can be clearly differentiated in the contracture curves (Sunano et al., 1977; Sunano and Shimodan, 1981). The phasic contraction is rapid and transient, while the tonic contraction is sustained for a long time without an obvious change in tension. The height of tonic contraction is low compared with that of phasic contraction. It was demonstrated that these responses are a direct reaction of smooth muscle to high-K, though some factors might slightly modify the contracture (SUNANo and SHIMODAN, 1981). Thus, the vas deferens of guinea-pigs seems to be an appropriate preparation for studying the nature of phasic and tonic contractions. However, little is known of the role of $\mathrm{Ca}$ in the initiation of contraction of this preparation (SwAMY et al., 1976), especially in relation to the phasic and tonic contractions induced by high-K.

The present study was performed to investigate the role of $\mathrm{Ca}$, especially extracellular $\mathrm{Ca}$ in the initiation of the phasic and tonic contractions induced by high-K. For this purpose, the effects of the $\mathrm{Ca}$ antagonist as well as of multivalent cations were studied.

\section{METHODS}

Guinea-pig vasa deferentia were used as described by SunANo and SHIMODAN (1981). Preparations of $5 \mathrm{~mm}$ length were made from the middle portion of the vas deferens the tube of which was longitudinally cut open and vertically mounted in a $10 \mathrm{ml}$ organ bath made of glass. A modified Tyrode solution (SunANO and SHIMODAN, 1981), maintained as $37^{\circ} \mathrm{C}$, aerated with $95 \% \mathrm{O}_{2}$ and $5 \% \mathrm{CO}_{2}$ and kept at $\mathrm{pH} 7.2$ was used as a normal solution in the present experiments.

The solution of various $\mathrm{K}$ concentrations was made by replacing $\mathrm{NaCl}$ in normal Tyrode solution with $\mathrm{KCl}$ isotonically. The high- $\mathrm{K}$ solution used in the present experiments was made by replacing all $\mathrm{NaCl}$ in the normal Tyrode solution by $\mathrm{KCl}$. A Ca-free solution was made by removing all $\mathrm{Ca}$ from each solution. In the experiment with $\mathrm{Mn}$ and La ions, a Tris-buffer system (10 mM) was used and aerated with $100 \% \mathrm{O}_{2}$. The basic Tris-buffered solution was adjusted with small volumes of $\mathrm{HCl}$ to a $\mathrm{pH}$ of 7.2.

Tension developments and isotonic shortenings were measured, respectively, by a mechano-electronic transducer (Nihon Kohden, Tokyo) and by a displacement transducer (San-ei Sokki, Tokyo). Electrical activities were recorded by the sucrose gap method as reported by BüLBRING and BURNSTOCK (1960). Action potentials were also recorded by using an A-C mode with a time constant of 0.03 under high amplification, so that small action potentials could be recorded. 
Electrical and mechanical activities were simultaneously recorded by an inkwriting oscillograph (San-ei Sokki, Tokyo).

Preparations were incubated for $30 \mathrm{~min}$ in normal Tyrode solution. Thereafter, contractures were produced repeatedly with high-K solution until the contractile responses became reproducible. The interval between successive contractures was about $30 \mathrm{~min}$.

Verapamil used in the experiments was kindly supplied by Eisai Pharm. Co., Ltd., Tokyo.

\section{RESULTS}

\section{1) Electrical and mechanical activities in high-K-induced contracture}

Figure 1 illustrates the change of membrane potential, action potential and tension development observed when the preparation was immersed in high-K solution.

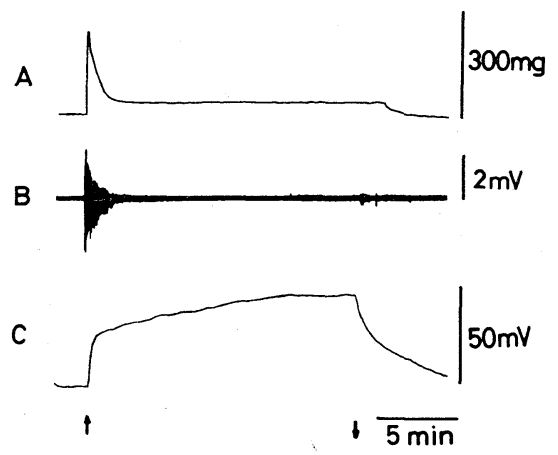

Fig. 1. Changes in electrical activities and tension induced by high-K solution. A: tension. B: electrical activities recorded by AC amplifier. C: membrane potential change. High-K solution was applied at the upward-pointing arrow and washed out with normal solution at the downward-pointing arrow.

As shown in this figure, phasic contraction was associated with rapid depolarization of the membrane while tonic contraction appeared to be related to sustained membrane depolarization. In A-C mode recording, which was applied to observe spike potentials of low amplitude, a number of action potentials were observed during the depolarizing phase of the membrane induced by high-K. The amplitude of action potentials decreased as membrane depolarization advanced, and disappeared 1-2 min after the application of high-K solution. At the same time, phasic contraction ceased and became tonic contraction. Reintroduction of normal Tyrode solution caused repolarization of the membrane and complete relaxation of the muscle. 
A

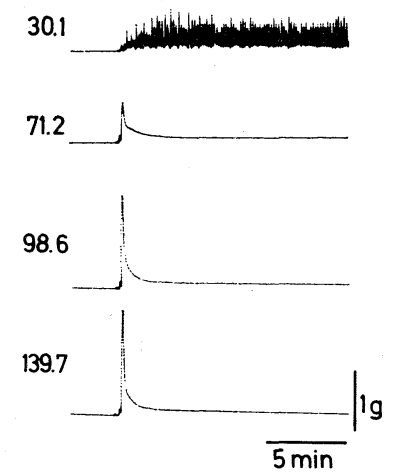

B

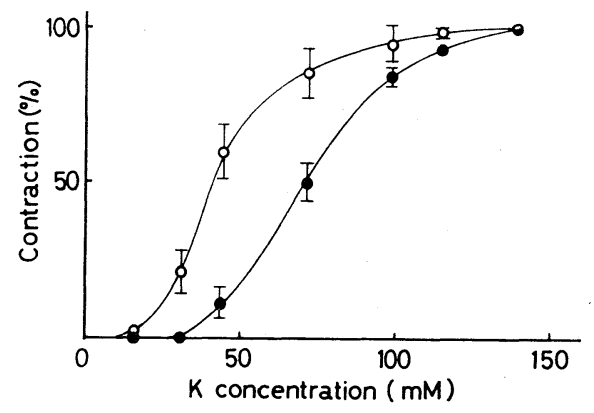

Fig. 2. The relation between the concentration of elevated $\mathrm{K}$ and the height of the phasic and tonic contractions. A: tension development induced by sudden elevation of $\mathrm{K}$ concentration as indicated on the left side of each figure. B: relation between $\mathrm{K}$ concentration and contraction height. The contraction height of the phasic and tonic contraction induced by $139.7 \mathrm{~mm} \mathrm{~K}$ was taken as $100 \%$ and each point respectively was calculated as a percentage of this height. Closed circles: the phasic contration. Open circles: the tonic contraction. Vertical bars represent the value of SE $(n=6)$.

2) Relationship between high-K-induced contracture and elevating external $K$ concentration

Figure 2 shows the relationship between the height of phasic and tonic contractions of the contracture and $\mathrm{K}$ concentration which was elevated suddenly. When the concentration of $\mathrm{K}$ ion in the solution was lower than $20 \mathrm{~mm}$, obvious phasic and tonic contractions were not observable. The elevation of $\mathrm{K}$ concentration to 20 or $40 \mathrm{~mm}$ resulted in the appearance of spontaneous contractions, and the basic tension increased slightly. The typical phasic contraction appeared at about $40 \mathrm{~mm}-\mathrm{K}$, reached half-maximum height at $70 \mathrm{~mm}-\mathrm{K}$, and attained its maximum at $139.7 \mathrm{~mm}$. Tonic contraction appeared at a $\mathrm{K}$ concentration lower than $20 \mathrm{~mm}$, reached half-maximum at $40 \mathrm{~mm}$ and attained its maximum at $100 \mathrm{~mm}$. Thus, it was shown that a higher concentration of $\mathrm{K}$ ion was required to initiate phasic contraction than to initiate tonic contraction.

When the external $\mathrm{K}$ concentration was gradually increased to $139.7 \mathrm{~mm}$, no phasic contraction was observed even at a high concentration, while tonic contraction appeared and increased with the elevation of $\mathrm{K}$ concentration (Fig. 3A, B)

In the experiment shown in Fig. 4, the $\mathrm{K}$ concentration was first elevated to a certain level (first step) and then to $139.7 \mathrm{~mm}$ (second step). When the K concentration of the first step was higher than $30 \mathrm{~mm}$, the phasic contraction observed at the second step decreased with the increase in $\mathrm{K}$ concentration of the first step; $v i s$ - $a$-vis with the decrease of the second step. Thus, no phasic contraction was 
A

a

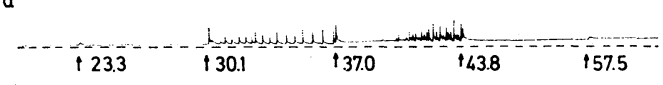

b

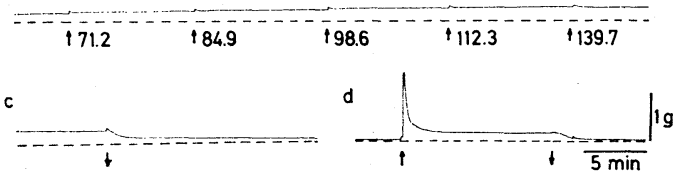

B

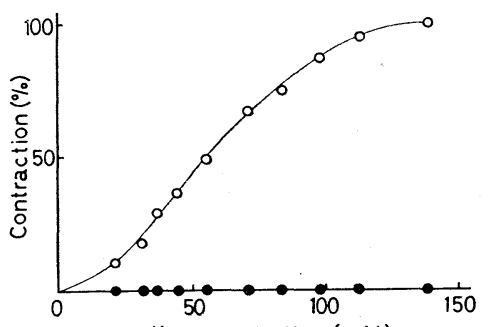

$\mathrm{K}$ concentration $(\mathrm{mM})$

Fig. 3. Tension development by gradual increase of $\mathrm{K}$ concentration. A: tension development by gradual increase in $\mathrm{K}$ concentration as indicated by the numbers. $a, b$, and $c$ are continuous recording. Control high-K-induced contracture is shown in d. Upward arrows and downward arrows in each figure indicate respectively the application and the wash-out of elevated $\mathrm{K}$ solution. $\mathrm{B}$ : the relationship between $\mathrm{K}$ concentration and the height of the phasic (closed circles) and tonic (open circles) responses induced by gradual increase in $\mathrm{K}$. Note that no phasic contraction was induced by this procedure. The height of the phasic and tonic contraction of control high-K contracture $(A, d)$ was set as $100 \%$.

A

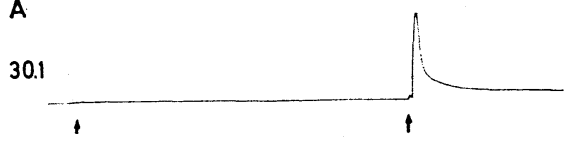

43.8

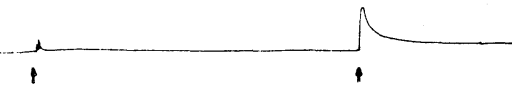

98.6

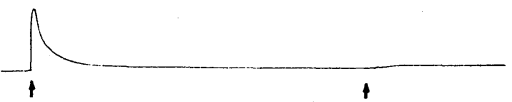

139.7

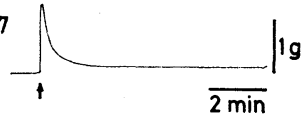

B

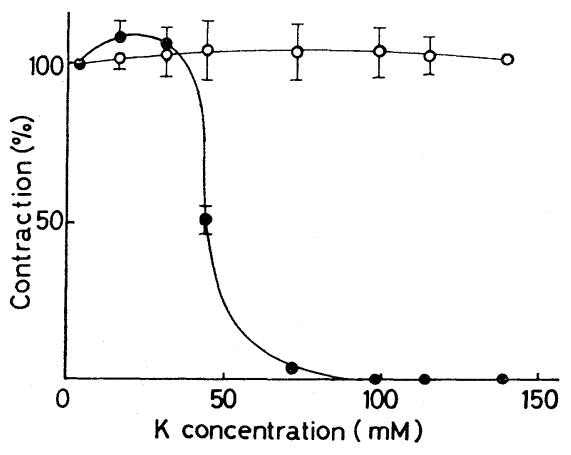

Fig. 4. High-K-induced contracture of the preparation incubated in a solution of elevated $\mathrm{K}$. A: at the first arrow, $\mathrm{K}$ concentration was elevated to the level indicated on the left side of each figure, after which high-K solution was applied (second arrow). B: the relation between the $\mathrm{K}$ concentration of the preincubated solution and the height of phasic and tonic contraction induced by the application of high-K solution. The height of the phasic and tonic contraction of high-K-induced contracture was set as $100 \%$. Vertical bars represent the value of SE $(n=6)$.

observed at the second step when $\mathrm{K}$ concentration of the first step was increased to higher than about $100 \mathrm{~mm}$ (Fig. 4A). The tonic component measured after the second step was not significantly affected and was almost the same as that 
A

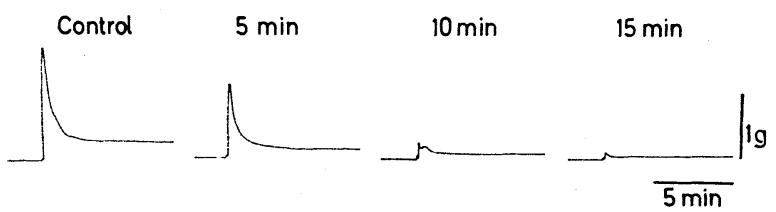

B

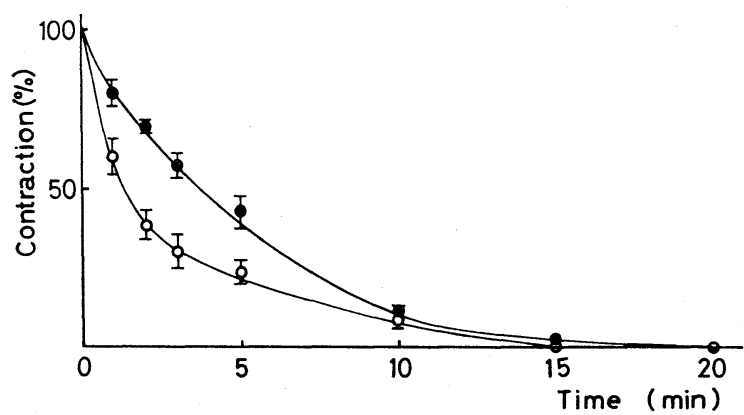

Fig. 5. Effects of Ca removal on high-K-induced contracture. A: high-K-induced contractures after various periods of incubation in $\mathrm{Ca}$-free Tyrode solution as indicated on the step of each figure. Ca-free high-K solution was used to initiate contracture. B: the relationship between the period of incubation in Ca-free solution and the height of phasic (closed circles) and tonic (open circles) contraction. The height of the phasic and the tonic contraction of control $\mathrm{K}$ contracture was taken as $100 \%$. Vertical bars represent the value of $\mathrm{SE}(n=6)$.

observed in the control high-K-induced contracture. These results are summarized in Fig. 4B.

\section{3) Extracellular $\mathrm{Ca}$ and $\mathrm{K}$-contracture}

High-K-induced contracture was abolished by the removal of $\mathrm{Ca}$ from the incubation medium. As shown in Fig. 5, the height of both phasic and tonic contractions decreased with the time of incubation in Ca-free solution, and both phasic and tonic responses disappeared after 15 to $20 \mathrm{~min}$. The decrease in height of contracture was accelerated by the addition of ethyleneglycol-bis- $(\beta$ aminoethyl ether)- $N, N^{\prime}$-tetraacetic acid (EGTA), and, in the presence of $2 \mathrm{~mm}$ of EGTA, both contractions disappeared within $5 \mathrm{~min}$. When $\mathrm{Ca}$ was removed in the course of tonic contraction, tension disappeared within 5 min of the absence and within $2 \mathrm{~min}$ of the presence of EGTA ( $2 \mathrm{mM})$.

Figure 6 shows the relation between the height of the phasic and the tonic components, and the extracellular $\mathrm{Ca}$ concentration observed in both isometric and isotonic measurements. In isometric measurement, phasic contraction appeared at a $\mathrm{Ca}$ concentration of $10^{-5} \mathrm{M}$ and showed an S-shaped dependence on $\log (\mathrm{Ca})_{\mathrm{o}}$, showing its maximum at a concentration between 1 and $2 \times 10^{-3} \mathrm{M}$. Tonic contraction appeared at a concentration of $10^{-5} \mathrm{M}$, and achieved its maximum at $10^{-2} \mathrm{M}$ (Fig. 6A). The tonic contraction observed in isotonic measure- 
A

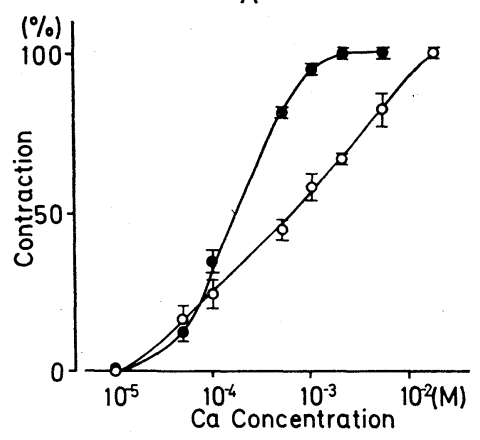

B

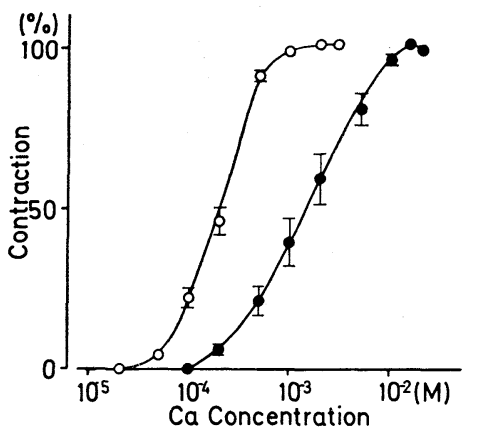

Fig. 6. Relation between $\mathrm{Ca}$ concentration and the height of the phasic and the tonic contraction studied by isometric measurement (A). Relation between Ca concentration and the height of the tonic contraction studied by isotonic measurement (B). A; Closed circles: the height of phasic contraction. Open circles: the height of tonic contraction. Each point was expressed as a percentage of maximum. Vertical bars represent the value of SE $(n=10)$. B; Open circles: isotonic measurement. The experiments were performed in a cumulative way using a high-K depolarized preparation. Note the difference of $\mathrm{Ca}$ sensitivity between the two modes of measurement. Vertical bars represent the value of $\mathrm{SE}(n=6)$.

ment under loading of $0.25 \mathrm{~g}$ showed higher sensitivity to $\mathrm{Ca}$ than the phasic one and its maximum was achieved at $10^{-3} \mathrm{M}$ which was about 10 times lower than the concentration for the maximum of isometric recording (Fig. 6B).

Phasic and tonic contractions could be initiated by the addition of $\mathrm{Ca}$ to a Ca-depleted preparation in high-K solution. In the experiment shown in Fig. 7b, a very high concentration $(1 \mathrm{M})$ of $\mathrm{Ca}$ was added to make a final concentration of $5 \times 10^{-3} \mathrm{M}$. This procedure was necessary to initiate a high amplitude of phasic contraction whereas tonic contraction height was dependent on the final $\mathrm{Ca}$ concentration regardless of the mode of application. High concentration $\left(5 \times 10^{-3} \mathrm{M}\right)$ of $\mathrm{Ca}$ itself could not induce a high amplitude of contraction when applied during the course of tonic contraction as shown in (a) of Fig. 7 and as expected from Fig. 6.

\section{4) Effect of verapamil on high-K-induced contracture}

High-K-induced contracture was inhibited by verapamil (Fig. 8). In the presence of $10^{-5} \mathrm{M}$ verapamil, reduction of the height of phasic contraction by $51 \pm 2.4 \%$ of the control and of that of tonic contraction by $90 \pm 2.4 \%$ was observed. Thus, it was shown that tonic contraction was about 10 times more sensitive to verapamil than phasic contraction, though a higher concentration $\left(10^{-3} \mathrm{M}\right)$ of verapamil abolished both phasic and tonic contractions. Recovery from verapamil treatment was slow, with $2-3 \mathrm{hr}$ or more being necessary for complete recovery. Application of verapamil of $10^{-5} \mathrm{M}$ during high-K-induced 

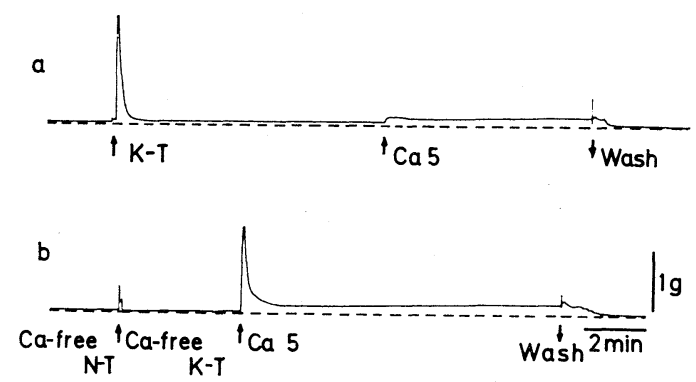

Fig. 7. Ca-induced contracture of a depolarized preparation. a: Ca concentration was increased by $5 \mathrm{~mm}$ during the course of the tonic component. b: the preparation was immersed in a Ca-free Tyrode solution for $20 \mathrm{~min}$, then in a Ca-free high-K solution for $4 \mathrm{~min}$. After these procedures, $1 \mathrm{~m} \mathrm{Ca}$ was added to the preparation to make a final concentration of $5 \mathrm{~mm}$. Wash: wash out with normal Tyrode solution.

A

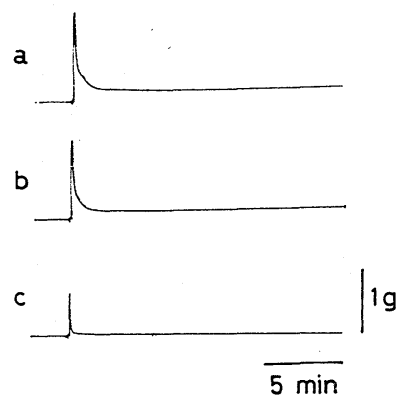

B

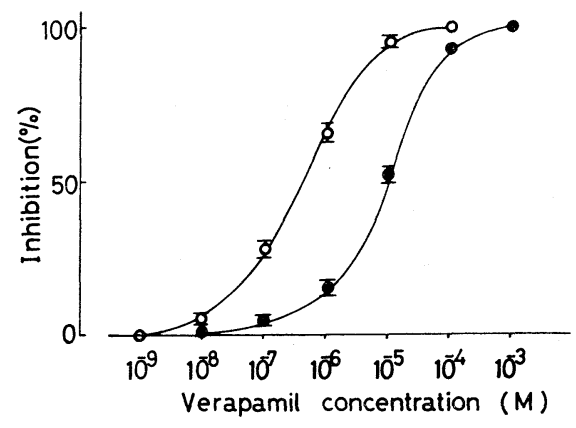

Fig. 8. Effects of verapamil on high-K-induced contracture (A) and the dose-response curve (B). a: control high-K-induced contracture. b: high-K contracture in the presence of $10^{-7} \mathrm{M}$ of verapamil. c: contracture in the presence of $10^{-5} \mathrm{M}$ of verapamil. Closed circles: phasic contraction. Open circles: tonic contraction. Vertical bars represent the value of $\operatorname{SE}(n=10)$.

contracture produced almost complete relaxation.

\section{5) Effect of manganese and lanthanum ions}

Manganese of $2 \mathrm{~mm}$ was not sufficient to abolish high-K-induced contracture, although it reduced the height of phasic and tonic contractions (Fig. 9). In the presence of $4 \mathrm{~mm}$ of $\mathrm{Mn}$, the first application of high-K solution failed to initiate either phasic or tonic contractions. However, the second application of high-K solution caused gradual elevation of tension which corresponded to tonic contraction. Tonic contraction became larger with the number of repetitions. A small phasic contraction reappeared from the third application of high-K solution and increased in height with the number of repetitions, though it was still highly depressed and slowed (Fig. 9c). 


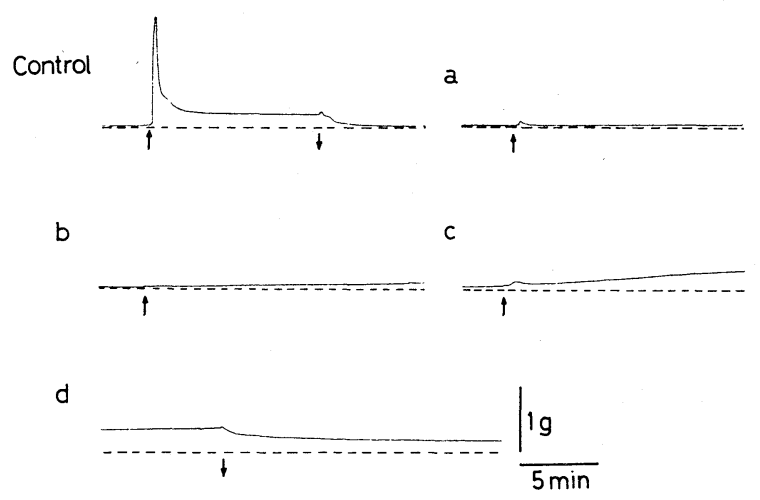

Fig. 9. The effects of manganese on high-K-induced contracture. a, b, and $\mathrm{c}$ : the first, second, and third application of high-K solution in the presence of $2 \mathrm{~mm}$ manganese. $\mathrm{d}$ : continuous recording of $\mathrm{c}$, high-K solution was washed out by normal Tyrode solution containing $2 \mathrm{~mm}$ manganese. Note the elevation of basic tension in normal Tyrode solution.

It should also be noted that the basic tension obtained in normal solution increased gradually in the presence of $\mathrm{Mn}$ and, after 3 repetitions, the tension in the normal solution was higher than that of the tonic contraction of control high$\mathrm{K}$-induced contracture obtained in the absence of $\mathrm{Mn}$. Similar results were obtained in the presence of $4 \mathrm{~mm}$ La.

Slow elevation of the basic tension initiated by high-K was also observed in the absence of $\mathrm{Ca}$ when $\mathrm{Mn}$ or $\mathrm{La}$ was present. The addition of $\mathrm{Mn}$ or $\mathrm{La}$ to the preparation incubated in $\mathrm{Ca}-\mathrm{free}$ high-K solution also caused very slow tension development.

\section{DISCUSSION}

High-K-induced contractures of guinea-pig vas deferens are composed of a phasic component and a tonic component which can be clearly distinguished (Westfall et al., 1972; SunANo and Miyazaki, 1975; Sunano et al., 1977). It was also shown that these responses are due to the direct reaction of smooth muscle to high-K, though some other factors can influence the contracture slightly (SUNANO and SHIMODAN, 1981).

In the present study on electrical activities accompanying the mechanical events, it could be demonstrated that both rapid depolarization and the burst of spike potential contribute to the phasic contraction. JoHNisH and SunANo (1978) have reported that the degree of contribution of the rapid depolarization or of the burst of action potentials varied among some types of smooth muscle. In vas deferens, the burst of spike potential could be the major cause of phasic contraction, since i) the time-course of the burst is similar to that of phasic contraction, as observed in the A-C mode of recording, ii) it could be initiated under 
moderate concentration of verapamil which inhibits the contraction due to rapid depolarization, leaving the contraction inhibited by action potential unaffected (JoHNISHI and SUNANO, 1978), iii) it was abolished in the presence of Mn or La which blocks action potential, iv) the height of the twitch contraction or the phasic contraction evoked by the electrical stimulation was similar to that of high-Kinduced contracture and much higher than that of the tonic contraction (SUNANO et al., 1977).

The size of the step of elevation of $\mathrm{K}$ concentration had an important role in the initiation of phasic contraction. In fact, a negative dependence was observed between the $\mathrm{K}$ concentration of the solution applied prior to application of high-K solution and the height of the phasic contraction, with no phasic contraction being observed when the preparations were preincubated in a solution of $\mathrm{K}$ concentration higher than $70 \mathrm{~mm}-\mathrm{K}$. This may be due partly to inactivation in elevated $\mathrm{K}$ as reported by Frankenhaeuser and LäNNERGREN (1967). Depression of action potential in elevated K (Holman, 1958; Kuriyama and TomitA, 1965) can also be the cause of the depression of phasic contraction. It is, however, not possible to perform these experiments under a condition in which action potential is blocked, since the procedures or agents which block the action potential of smooth muscle also block Ca influx (SHIBATA, 1969; CASTEELs et al., 1972; MAYER et al., 1972; VAN BREEMEN et al., 1973) and depress high-K-induced contracture (Imai and TAKeda, 1967; Sunano and Miyazaki, 1968; Swamy et al., 1976; JOHNISHI and SUNANO, 1978). It is, however, more probable that the depression of phasic contraction could be caused by the decrease in the number and/or the height of the spike potentials observed as an integrated burst in the course of depolarization (Holman, 1958; KURIYAMA and TOMITA, 1965).

The phasic contraction of the high-K-induced contracture of guinea-pig vas deferens was abolished by the removal of $\mathrm{Ca}$ from the incubation medium or by treatment with verapamil, $\mathrm{Mn}$, or La. These treatments cause an abolition of the action potential in smooth muscle, and these action potentials might induce the above-described phasic contraction. Therefore, it still cannot be concluded whether phasic contraction is initiated by influxed $\mathrm{Ca}$ or by released $\mathrm{Ca}$ from certain binding sites caused by action potential. In any case, however, it can be concluded that the first step in abolition of phasic contraction is the blokage of $\mathrm{Ca}$ influx, since it is known that the action potential of this muscle is brought about by the influx of $\mathrm{Ca}$ and this $\mathrm{Ca}$ can initiate contraction (GoODFORD, 1967; SunANo and MryazaKI, 1968; LÜllmann and Mohns, 1969).

Thus, it seems probable that phasic contraction was initiated by influxed $\mathrm{Ca}$ involved in the burst of spike potentials. This $\mathrm{Ca}$, then, might be taken up by some intracellular binding sites or pumped out through the cell membrane by the Ca-activated transport mechanism, through which relaxation would be brought about (CASTEELS and VAN BREEMEN, 1975; JANIS et al., 1977).

Although phasic contraction could also be initiated in a preparation which 
has been depolarized i.e., no spike burst would be elicited (Fig. 7), a similar explanation in the case of high-K-induced phasic contraction can be made. The addition of a very high concentration of $\mathrm{Ca}$ was required to initiate phasic contraction even though the final concentration was the same. In this case, the added Ca could enter the cell through the depolarized cell membrane abruptly and cause a contraction in a similar manner to the case of a burst of action potential and/or sudden depolarization of the membrane. The intracellular Ca concentration could be reduced by the mechanism which is activated by the increase in intracellular free $\mathrm{Ca}$ concentration as described above. Thus, phasic contraction could be formed. This assumption is supported by the result that, when $\mathrm{Ca}$ concentration was elevated gradually, it could not cause a tension development as high as that of phasic contraction even at very high concentrations as shown in the doseresponse relationship. The results also support the possibility that $\mathrm{Ca}$ which enters the cell through the plasma membrane abruptly could initiate phasic contraction, since $\mathrm{Ca}$ was added to the extracellular fluid of the $\mathrm{Ca}$-depleted preparation.

Tonic contraction would be caused by sustained depolarization of the membrane and would be dependent on the degree of depolarization as indicated in the experiment with elevated $\mathrm{K}$ concentration. Tonic contraction by high- $\mathrm{K}$ was not influenced by $\mathrm{K}$ concentration of a preincubation medium, and, when $\mathrm{K}$ concentration was elevated gradually, its height increased depending on the $\mathrm{K}$ concentration. Thus, no inactivation was observed in the tonic contraction.

Tonic contraction was also sensitive to extracellular $\mathrm{Ca}$ and was abolished by the removal of $\mathrm{Ca}$. It was depressed in the presence of verapamil, $\mathrm{Mn}$ or $\mathrm{La}$; the agents which have been known to be blockers of Ca influx (SHIBATA, 1969; MAYER et al., 1972; VAN BREEMEN et al., 1973). The addition of Ca to a preparation which had been depolarized and in which $\mathrm{Ca}$ had been depleted, also initiated tonic contraction. These results strongly suggest that tonic contraction is initiated by influxed $\mathrm{Ca}$ from extracellular fluid.

Sustained depolarization causes a continuous increase in Ca influx (URAKAWA and Holland, 1964; MAYer et al., 1972; VAN Breemen et al., 1973; LAMMEL, 1977) and this $\mathrm{Ca}$ also stimulates $\mathrm{Ca}$ extrusion or uptake of $\mathrm{Ca}$ into certain intracellular binding sites (VAN BREEMEN et al., 1975; JANIS and DANIEL, 1977). Thus, intracellular Ca concentration would stay at a certain level due to the equilibrium of these two processes. This could be an explanation for the constant tension of the tonic contraction.

The difference in $\mathrm{Ca}$ sensitivity of tonic contraction measured isotonically and isometrically (Fig. 6) may be one of the explanations for the difference in the height of the tonic contraction observed in each measurement (SuNANO and SHIMODAN, 1981); i.e., higher tonic contraction related to higher sensitivity in isotonic recording, and lower tonic contraction related to lower sensitivity.

Gradual increase in tension was observed in the presence of $\mathrm{Mn}$ or La after 
the second or the third application of high-K solution. The basic tension observed after washing with high- $\mathrm{K}$ solution also increased. The results may be explained by the leakage influx of $\mathrm{Ca}$ and the inhibition of the extrusion or its uptake by intracellular Ca accumulation sites (MAYER et al., 1972; VAN BREEMEN et al., 1972, 1973). It is, however, difficult to explain the sustained tension development in a Ca-free solution with this assumption. An alternative explanation for tension development in a Ca-free solution is a direct activation of the contraction of smooth muscle by these ions (SHibata, 1969).

It may be concluded that both phasic and tonic contraction are initiated by influxed $\mathrm{Ca}$ and that sustained tonic contraction is brought about by the equilibrated level of intracellular $\mathrm{Ca}$ which is maintained by constant influx and extrusion. The observation that $\mathrm{Ca}$ influx increases during both phasic and tonic contractions of intestinal smooth muscle (Triggle and Triggle, 1976) may support this assumption.

We wish to thank Prof. H. Lüllmann of Department of Pharmacology of University of Kiel for his reading and criticism of the manuscript. We are also grateful to Prof. E. Miyazaki for his support and encouragement.

\section{REFERENCES}

BüLbRING, E. and Burnstock, G. (1960) Membrane potential changes associated with tachyphylaxis and potentiation of the response to stimulating drugs in smooth muscle. $B r . J$. Pharmacol., 15: 611-624.

Casteels, R., VAn Breemen, C., and Mayer, C. J. (1972) A study of the calcium distribution in smooth muscle cells of the guinea-pig taenia coli using $\mathrm{La}^{3+}$. Arch. Int. Pharmacodyn. Ther., 199: 193-194.

Casteels, R. and VAn BReEmen, C. (1975) Active and passive $\mathrm{Ca}^{2+}$ fluxes across cell membranes of the guinea-pig taenia coli. Pflügers Arch., 359: 197-207.

Chapman, J. B. and Holman, M. E. (1968) Potassium contractures in the ureter of the guineapig. Aust. J. Exp. Biol. Med. Sci., 46: 503-514.

Frankenhaeuser, B. and LänNergren, J. (1967) The effect of calcium on the mechanical response of single twitch muscle fibers of Xenopus laevis. Acta Physiol. Scand., 69: 242-254.

Goodford, P. J. (1967) The calcium content of the smooth muscle of the guinea-pig taenia coli. J. Physiol. (Lond.), 192: 145-157.

Holman, M. E. (1958) Membrane potentials recorded with high-resistance micro-electrodes; and the effects of changes in ionic environment on the electrical and mechanical activity of the smooth muscle of the taenia coli of the guinea-pig. J. Physiol. (Lond.), 141: 464-488.

IMAI, S. and TAKEDA, K. (1967) Actions of calcium and certain multivalent cations on potassium contracture of guinea-pig's taenia coli. J. Physiol. (Lond.), 190: 155-169.

JANis, R. A., Crankshaw, D. J., and DANiEL, E. E. (1977) Control of intracellular $\mathrm{Ca}^{2+}$ activity in rat myometrium. Am. J. Physiol., 232: C50-C58.

JANIS, R. A. and DANIEL, E. E. (1977) $\mathrm{Ca}^{2+}$ transport by subcellular fractions from smooth muscle. In: The Biochemistry of Smooth Muscle, ed. by StePHEns, N. L. University Park Press, Baltimore, London, and Tokyo, pp. 653-671.

JoHnishi, J. and SunANO, S. (1978) The role of membrane electrical activities and extracellular calcium in high-K-induced contracture of guinea pig ureter. Jpn. J. Physiol., 28: 1-16. 
Kuriyama, H. and Tomita, T. (1965) The responses of single smooth muscle cells of guineapig taenia coli to intracellularly applied currents, and their effect on the spontaneous electrical activity. J. Physiol. (Lond.), 178: 270-289.

Kuriyama, H., Osa, T., Ito, Y., Suzuki, H., and Mishima, H. (1976) Topical difference in excitation and contraction between guinea pig stomach muscles. In: Physiology of smooth muscle, ed. by Bülbring, E. and Shuba, M. F. Raven Press, New York, pp. 185-196.

LAMMEL, E. (1977) ${ }^{45}$ Ca-uptake of stomach smooth muscle during different modes of activation. In: Excitation-Contraction Coupling in Smooth Muscle, ed. by CASTEELS, R. et al. Elsevier, North Holland Biochemical Press, Amsterdam, pp. 273-277.

Lüllmann, H. and MoHns, P. (1969) The Ca metabolism of intestinal smooth muscle during forced electrical stimulation. Pflügers Arch., 308: 214-224.

Mayer, C. J., VAN BreEmen, C., and CASTeEls, R. (1972) The action of lanthanum and D600 on the calcium exchange in the smooth muscle cells of the guinea-pig taenia coli. Pflügers Arch., 337: 333-350.

Rosenberger, L. B., Ticku, M. K., and Triggle, D. J. (1979) The effects of $\mathrm{Ca}^{2+}$ antagonists on mechanical responses and $\mathrm{Ca}^{2+}$ movements in guinea pig ileal longitudinal smooth muscle. Can. J. Physiol. Pharmacol., 57: 333-347.

ShibatA, S. (1969) Effects of $\mathrm{Mn}^{++}$on ${ }^{45} \mathrm{Ca}$ content and potassium-induced contraction of the aortic strip. Can. J. Physiol. Pharmacol., 47: 827-829.

SunANo, S. and MryazAKI, E. (1968) The initiation of contraction by extracellular calcium in the smooth muscle of the guinea-pig taenia coli. Experientia, 24: 364-365.

SunAno, S. and MiYazAKI, E. (1975) Study on the potassium contracture in smooth muscle. J. Physiol. Soc. Jpn., 37: 215-216.

Sunano, S., MoriYa, M., and Mochizuki, Y. (1977) Effects of dantrolene sodium on some types of visceral muscles. Folia Pharmacol. Jpn., 73: 665-674.

SunANo, S. and SHimodan, M. (1981) Factors affecting high-potassium-induced contracture of guinea-pig vas deferens. Jpn. J. Physiol., 31: 1-13.

Swamy, V. C., Triggle, C. R., and Triggle, D. J. (1976) The effects of lanthanum and thalium on the mechanical responses of rat vas deferens. J. Physiol. (Lond.), 254: 55-62.

Triggle, C. and Triggle, D. J. (1976) An analysis of the action of cations of the lanthanide series on the mechanical responses of guinea-pig ileal longitudinal muscle. $J$. Physiol. (Lond.), 254: 39-54.

Urakawa, N. and Holland, W. C. (1964) $\mathrm{Ca}^{45}$ uptake and tissue calcium in K-induced phasic and tonic contraction in taenia coli. Am. J. Physiol., 207: 873-876.

Van Breemen, C., Farinas, B. R., Gerba, P., and McNaughton, E. D. (1972) Excitationcontraction coupling in rabbit aorta studied by the lanthanum method for measuring cellular calcium influx. Circ. Res., 30: 44-54.

Van Breemen, C., Farinas, B. R., Casteels, R., Gerba, P., Wuytack, F., and Deth, R. (1973) Factors controlling cytoplasmic $\mathrm{Ca}^{2+}$ concentration. Philos. Trans. R. Soc. Lond. (Biol.), 265: 57-71.

Van Breemen, C., Wuytack, F., and Casteels, R. (1975) Stimulation of ${ }^{45}$ Ca efflux from smooth muscle cells by metabolic inhibition and high-K depolarization. Pflügers Arch., 359: 183-196.

Westfall, D. P., McClure, D. C., and Fleming, W. W. (1972) The effects of denervation, decentralization and cocaine on the response of the smooth muscle of the guinea-pig vas deferens to various drugs. J. Pharmacol. Exp. Ther., 181: 328-338. 